Article

\title{
Applying Axial Symmetries to Historical Silk Fabrics: SILKNOW's Virtual Loom
}

\author{
Mar Gaitán ${ }^{1, *(\mathbb{D}}$, Cristina Portalés ${ }^{2} \mathbb{D}$, Javier Sevilla ${ }^{2} \mathbb{C}$ and Ester Alba ${ }^{1}(\mathbb{D}$ \\ 1 Department of Art History, Universitat de València, 46010 València, Spain; esther.alba@uv.es \\ 2 Institute of Robotics and Information and Communication Technologies (IRTIC), Universitat de València, \\ 46980 València, Spain; cristina.portales@uv.es (C.P.); javier.sevilla@uv.es (J.S.) \\ * Correspondence: M.Gaisal@uv.es; Tel.: +34-963983413
}

Received: 12 March 2020; Accepted: 16 April 2020; Published: 5 May 2020

check for updates

\begin{abstract}
Symmetry is part of textile art in patterns and motifs that decorate fabrics, which are made by the interlacement of warp and wefts. Moreover, the 3D representation of fabrics have already been studied by some authors; however, they have not specifically dealt with preserving historical weaving techniques. In this paper, we present the SILKNOW's Virtual Loom, a tool intended to document, preserve and reproduce silk historical weaving techniques from the 15th to the 19th centuries. We focus on the symmetry function and its contribution to art history, textile conservation, and modern design. We analyzed 2028 records from Garin 1820 datasets-a historical industry that still weaves with these techniques-and we reconstructed some historical designs that presented different types of defects. For those images (including fabrics and drawings) that had a symmetrical axis, we applied the symmetry functionality allowing to reconstruct missing parts. Thanks to these results, we were able to verify the usefulness of the Virtual Loom for conservation, analysis and new interpretative advantages, thanks to symmetry analysis applied to historical fabrics.
\end{abstract}

Keywords: virtual loom; silk fabrics; symmetry analysis

\section{Introduction}

Symmetry is present in art from its very beginning, from Polykleitos, who was the first to write a book about proportions and their application in sculpture, to Ghiberti, Dürer and Leonardo, passing by Islamic art or Peruvian textiles ... from corner to corner of the globe, symmetry has always been related to beauty, order and the divine. Indeed, symmetry in art, as stated by Atival [1] (p.96), 'is at the most on the level of similarity of one degree or another'. In fabrics, a pattern is made by the interlacement of warps and wefts. In order to create symmetry, the warp lines up with either the weft axis or another warp in the motifs new position [2]. These motifs can be asymmetrical and symmetrical, or they can even be asymmetrical but presenting repetitions or symmetrical and repeated [3]. Motifs and patterns were widely spread across Europe and in many occasions, revivals were used.

In this paper, we deal with the 3D reconstruction of symmetric historical fabrics by means of the Virtual Loom [4], a computational tool that embeds historical weaving techniques in order to produce 3D models, given an input image. The Virtual Loom's graphical user interface is designed in such a way that is highly intuitive, guiding users through the process and making it possible for them to produce the models without any previous knowledge about textiles and/or old techniques. The definition and modeling of such techniques in the Virtual Loom has been possible thanks to close collaboration of experts in computer graphics, art history and old textiles (Figure 1). 


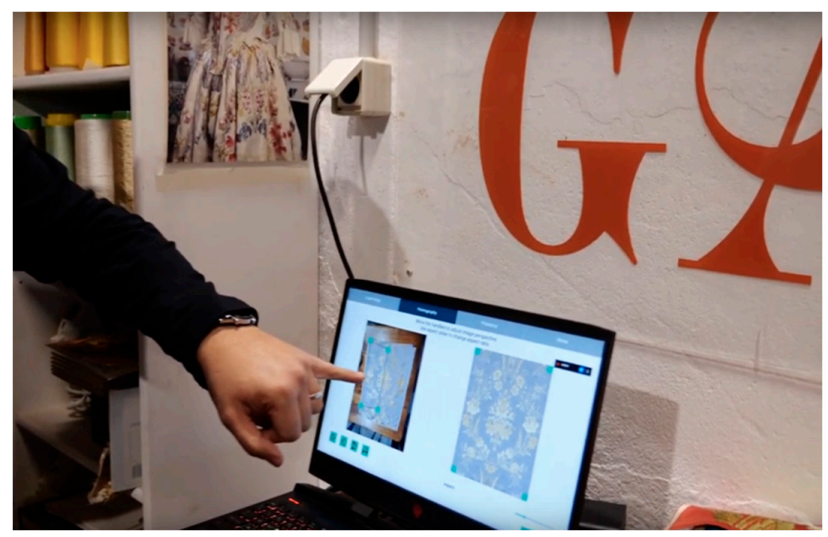

Figure 1. The Virtual Loom at Garin 1820, an artisanal factory that weaves with Jacquard looms from the 19 th century.

Furthermore, the 3D virtual modelling of artifacts is a common practice in cultural heritage; for instance, it has been used at archaeological sites, to reconstruct the non-existing elements $[5,6]$; to reconstruct the current shape of artifacts, including paintings [7], ceramics [8], statues [9,10], etc.; or to provide enhanced experiences at the museums level, by means of augmented reality technology [11,12]. Referring to textiles, some authors have already dealt with 3D representation textiles and clothes [13-17]. For instance, the work presented in [15] proposes a representation of knitted cloth at the yarn level, which treats yarn-yarn contacts as persistent, avoiding expensive contact handling altogether. However, not all of the authors deal with the internal structure of textiles at the yarn level, as this involves many challenges, e.g., the need for high computational performance. In the Virtual Loom, we are not focused on visually reproducing the aspect of yarns in detail or simulating how fabrics can be put together to make clothes, but on reproducing the historical weaving techniques of fabrics and making them interactive in real time.

There also exists a variety of software for the 3D virtual representation of textiles. For instance, the WiseTex software suite $[18,19]$ is an integrated tool for modeling textiles and textile composites, embedding a variety of software modules for the internal geometry, the virtual reality visualization, the resistance of textiles to tension, shear and compaction, etc. Another example is TexGen [20], which allows one to model the geometry of textile structures with a variety of properties, including textile mechanics, permeability and composite mechanical behavior. Other software tools are, e.g., Pointcarré Textile Software [21], STOLL M1 Plus [22] and iWeaveIt [23]. These software tools have similarities with the Virtual Loom, in the sense that they involve 3D representations of weaves for a fabric, taking a design into consideration. However, while other tools are usually intended to create designs and visualize them in 3D prior to the making of fabrics, in the Virtual Loom we start from the images of real fabrics, so we need to extract the design and apply weaves and weaving techniques in order to visualize them in 3D. In fact, one of the challenges of the Virtual Loom is to extract the design from images, which are of historical fabrics or technical drawings, and can vary in their resolution and acquisition characteristics, or even be damaged or incomplete. To aid in the reconstruction of fabrics, we have also implemented a symmetry functionality in the Virtual Loom, which is described in this paper.

There are other research works that present kinds of "virtual looms", such as in [24-26], but they are conceptually very different from our work. For instance, the works described in [24,25] do not make use of 3D graphics. On the other hand, in [26] a loom itself is reconstructed in 3D. They develop an interactive system based on Kinect technology to virtually build a Tujia brocade, which can only be accessed in an exhibition.

Going beyond the state-of-the-art, SILKNOW, an EU project funded under H2020 [27], created a Virtual Loom intended to document, preserve and reproduce silk historical weaving techniques from the 15th to the 19th centuries. Departing from images of textiles, it extracts the design and applies 
weaves and weaving techniques in order to visualize them in 3D. In fact, one of the challenges of the Virtual Loom is to extract the design form images, which are of historical textiles, and that can vary in their resolution and acquisition characteristics. Additionally, 3D representations were built, taking into account geometric and radiometric simplifications in order to improve graphics performance. With this, the Virtual Loom acts as a custodian of the collective memory, as silk fabrics and their designs are part of a vast and invaluable heritage associated with them (tangible and intangible heritage). In this paper, we present the advances of the Virtual Loom, focusing on its capacity to reproduce the symmetry of fabrics and its contribution to the history of art and textile preservation. We will make a brief review of symmetrical motifs in applied arts, as well as historical designs in silk. Lastly, we will give concrete examples of the application of the Virtual Loom in symmetry, specifically in fabrics from Garin 1820, a factory that continues weaving with 19th-century techniques and its part of SILKNOW consortium.

\section{Symmetry and Silk Fabrics}

In cultural history, the term symmetry has always been present, from the Bible in the Book of Kings where the Temple of King Solomon relates symmetry to the divine, to Greek philosophers Plato, who attributes in his Republic that symmetry (proportion) is the way to truth [28] or Aristotle, in whose Metaphysics communicates that the 'chief forms of beauty are order and symmetry and definiteness' [29]. It was not until the Hellenistic period that Polykleitos studied proportion, attributing, in his treatise "Canon", the mathematical relation between different parts of the human body and its application in sculpture. Vitruvius' work "Ten books about architecture", written in the second half of the 1st century BC, studied the relation between art and mathematics in the first surviving theoretical discussion of symmetry. During the Middle Ages, symmetry, in a symbolic way, was related to justice [30], while the sense of harmony and proportion were maintained. However, it was during the Renaissance that the return to classic art and philosophy led to the rediscovery of Vitruvius and reinterpreted symmetry making emphasis on proportions; in fact, Ghiberti used proportion and symmetry as synonyms, just as Piero della Francesca, Leonardo da Vinci, Alberti, Dürer and many others $[30,31]$. The Baroque brought new forms to apply symmetries, ellipsis, helicoidal columns, medallions in art and architecture. During the Neoclassical and Romanticism periods symmetries continued to be applied in designs, at the same time that symmetry was being applied to science.

On the other hand, the professionalization of artistic design applied to fabrics was achieved thanks to the incorporation of the academical system of fine arts to design studies, whose best-known cases are Lyon and Valencia. In this new teaching, scientific treatises applied to the arts were fundamental, especially those devoted to the representation of oblique, descriptive and axonometry perspectives. It is commonly assumed that the concept of bilateral symmetry is inherent to human perception [32] (p. 97), but the first usage of the term symmetry in a scientific context appeared in 1788 in a work by Gaspard Monge (1746-1818) [33]. Monge's system [34], based on studies of Girard De Sargues, author of the beginnings of projective geometry, consolidated the scientific language based on descriptive geometry, as it allows three-dimensional surfaces of objects to be represented on a two-dimensional surface [35]. This system projects a universal language that departs from the project's conception, to the person who is performing it and a system of signs linked to the mental distance between the object constructed and the observer. Monge understood that this learning was indispensable for the industry, as descriptive geometry is the instrument for industrial objects, just like perspective is the instrument that organizes human space [36].

When it comes to patterns, Gombrich [37] (p. 149) argues that a pattern can 'become an essential component of design if it is married with symbolism, theme, and motif'. Indeed, patterns are an essential part of aesthetics, that form more or less complex designs. Authors report that there are four kinds of symmetry [38-41]: translation, bilateral or reflection, rotation and glide reflection. A pattern can be described as the repetition of a motif, which can be symmetrical (whenever they have two or more identical parts) or asymmetrical (whenever it cannot be geometrically deconstructed in equal parts) [40-42]. Symmetrical patterns have a geometrical basis, and no matter how complex 
these patterns are, they will fall into one of the four kinds of transformations [38,39]. These are possible for a geometric object, depending on the set of geometric transforms available, and on what properties remain unchanged after a transformation. Brainerd [43] was the first archaeologist that used symmetry classification as an analytical tool, he applied it to aboriginal American ceramics, providing a classification of conventional design and providing the potential value of cross-cultural analysis by evidencing cultural exchanges, suggesting that his research might be applicable to other types of patterns studies. The translation is when a shape undergoes vertically, horizontally, or diagonally at regular intervals without changing the orientation of the motif. Rotation occurs when a motif undergoes repetition around a point in the plane, they are identified as divisions of 360 degrees. Reflection is characteristic of motifs, border patterns and all-over patterns, this happens when a motif is repeated across an imaginary line (best known as reflection axis) producing a mirror image, this type of symmetry is also called bilateral symmetry. Glide-reflection is a translation followed by a mirror reflection; it permits a motif to be repeated in one action through a combination of translation and reflection, in association with a glide-reflection axis. All four motions can be used to generate these patterns. Border patterns and all-over patterns may also be classified according to these four motions, making a total of seven primary classes of border patterns and seventeen classes possible for all-over patterns [3,41]. As per border patterns, only two-fold rotation (180 degrees) is possible, and only two-, three-, four- and six-fold rotations (180, 120, 90 and 60 degrees) are possible for all-over patterns. Finally, symmetrical motifs exhibit rotation and reflection symmetries. In the scope of this paper, we focus on axial geometries, also known as reflections; we also focus on flat designs (fabrics and technical drawings) that present border patterns and all-over patterns, applying to them axial or central symmetries. In the framework of this paper, we focus our attention on Garin's examples, a traditional fabric that weaves with Jacquard looms since 1820. Their 19th designs can be grouped in three different styles [44]: those with a symmetrical and central bouquet framed by a vegetable border; those arranged in the same way but with asymmetrical branches; and those that are woven from left to right (tres bolillo). From these three designs, we will focus on those that have central bouquets, with barely any movement, joined on their base and inscribed in a garland of floral and vegetable motifs which is arranged as a rhombus, such as the Francia and Rica.

\section{The Consideration of Symmetry in SILKNOW's Virtual Loom}

In fabrics, designs are made by the interlacement of warps and wefts, and in order to create symmetry, the warp lines up with either the weft axis or another warp in the motifs new position [3]. In Jacquard looms, punched cards determine which warp threads are lifted; if a pattern is repeated across the width of the fabric, the loom is threaded in a way that several wires from the harness are connected to a hook corresponding the holes of the punched card, either mirrored or repeatedly. These patterns were drawn by hand by artists, and later, transformed into a pattern on a grid paper. To assist in the subsequent process of translating the drawing into punched cards, the grid was marked with thicker lines to group the dots in sequences of 12 , the number of holes that could be punched in each line of the cards. The colors of the dotted paper rarely corresponded to the colors of the finished grid, since each pattern could be used for several different color combinations. The pattern was adapted according to the restrictions of the grid, since each position in the grid can only contain one color. The relation between modern computers and Jacquard looms is not new, in fact, Jacquard was the first to transform the binary basis of weaving into a language understandable for non-weavers [45], later on, Ada Lovelace will describe the Analytical Engine as weaver of algebraical patterns. SILKNOW continues with this tradition by creating a Virtual Loom.

The Virtual Loom is an open source software module that embeds historical weaving techniques in order to produce 3D models of textiles, given an input image with related information. A description of the first release version of the Virtual Loom can be found in [4,46]; the code can be accessed through the SILKNOW's GitHub repository [47], and online releases are also available at [48]. The Virtual Loom has been developed using the Unity3D engine, which provides a complete environment, where 
we have been able to develop the user interface and the 3D representation of a given fabric. It also allows us to unify the development process for different platforms (Standalone and Web). The image analysis is performed using the OpenCV plugin for Unity3D.

Figure 1 depicts a simplified workflow of the tool, where the input parameters for the Virtual Loom are an image of the fabric and related information (e.g., weaving technique). Once these parameters are loaded into the tool, users can extract the design by means of image analysis. In the example shown in Figure 2, the design has been subtracted by considering eleven zones, and each one is given a color defined by the user. At this point, they can also define the types of yarns and the basic weave for the background. There are seven types of yarns implemented in the Virtual Loom (variations of silk and silk with metal) and a total of 39 weaves (tabby, twill, satin and variations). The generated image, as well as the other parameters (e.g., yarns, weave, weaving technique) are then used to produce an interactive, 3D representation of the textile. This 3D model can also be exported into an STL format, for its printing in a standard 3D printer. A video tutorial on how to use the Virtual Loom is available in [49].

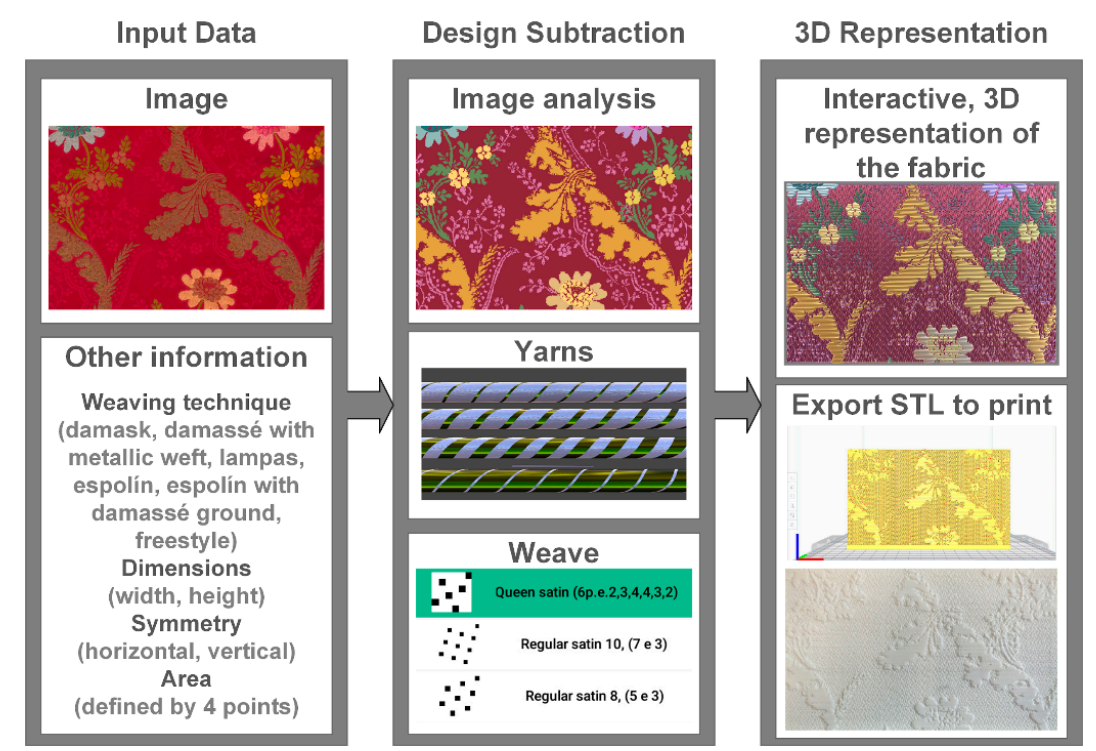

Figure 2. Basic workflow of the Virtual Loom: input data, design subtraction and 3D representation. The images depicted correspond to a fabric with the weaving technique espolín with damassé ground.

The techniques implemented so far in the Virtual Loom are the following ones: damask, damassé with metallic weft, lampas, espolín and espolín with damassé ground. Additionally, to expand the Virtual Loom to big audiences and the creative industries, we have introduced a weaving technique called "freestyle", from where all types of implemented weaves and modelled yarns can be chosen, in order to experiment with new forms of generating 3D models for a given design embedded in an image. The definition and computational modelling of such historical weaving techniques has been possible thanks to a tight collaboration among experts in computer engineering and domain experts related to the production of silk textiles.

For all techniques, users can also experiment by changing the color of the yarns, increasing/decreasing the number of yarns, increasing/decreasing the number of zones (of the design), mirroring an image (with a "symmetry" function) to complete a design, etc. The generated 3D models can be downloaded, as well as the design after the posterization of the image. Additionally, the Virtual Loom allows users to upload any image. Therefore, they can upload their own design, in order to virtually weave it and produce a 3D model.

In the scope of this paper, we focus our attention on the "symmetry" functionality, that allows mirroring an image through a vertical or horizontal axis, or both. Additionally, the original image can be rotated, the aspect ratio of the resulting image can be modified, the area of the original image can be 
selected with four points, and the original image can be flipped in any direction by reordering the four points. As mentioned above, for the image analysis of the Virtual Loom, we make use of the OpenCV plugin for Unity3D. To perform these operations, we mainly use planar homographies, which relate the transformation between two planes (up to a scale factor).

Within these combinations, interesting outputs can result. In Figure 3, symmetric images are produced by selecting different parameters. To better illustrate this fact, a sample image with the word "Symmetry" has been produced and processed with different combinations, to produce symmetric or mirrored images. For each example, the image on the left is the input image, and the four points (represented by green squares); the image on the right is the output image.

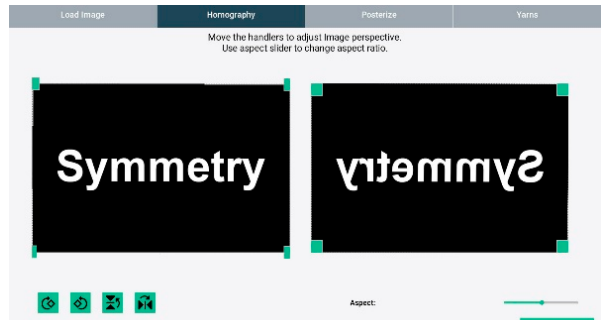

(a)

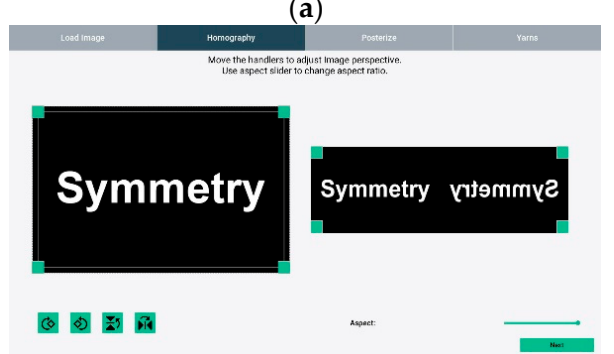

(c)

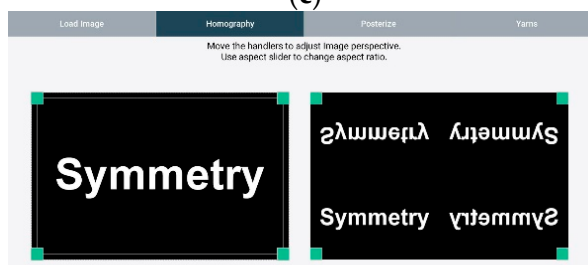

(4) ำ ถี

(e)

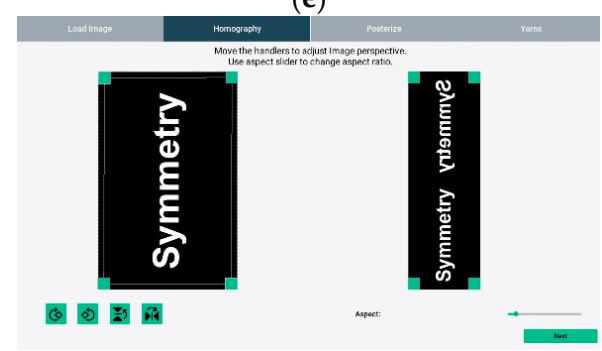

$(\mathrm{g})$

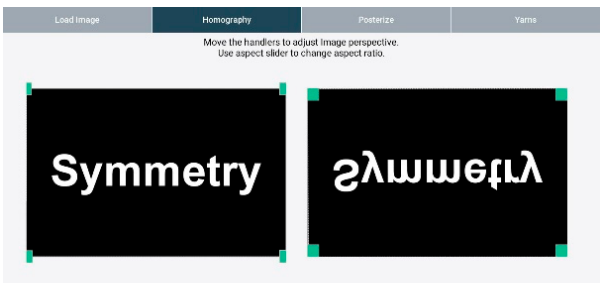

(c) क्ष प्र

(b)

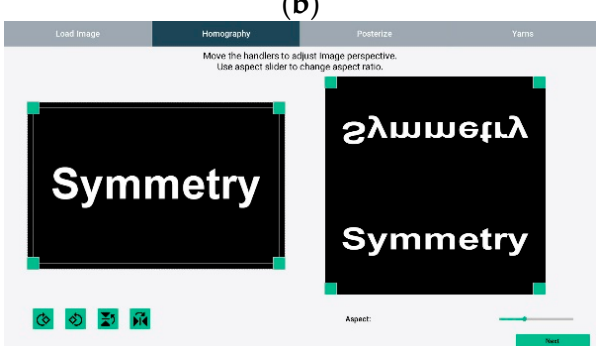

(d)

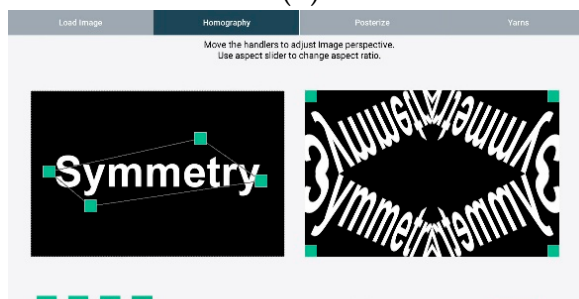

(f)

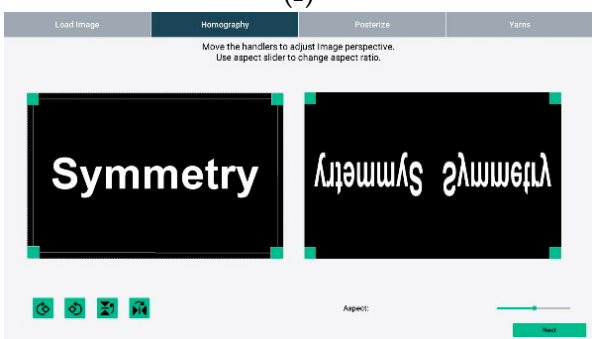

(h)

Figure 3. Results after mirroring an image with the word "Symmetry", where: (a) mirrored (left-right) image by reordering the four points; (b) mirrored (up-down) image by reordering the four points; (c) symmetry in the vertical axis, aspect ratio changed (with respect to the original image); (d) symmetry in the horizontal axis, aspect ratio changed; (e) Symmetry in the vertical and horizontal axis; (f) symmetry in the vertical and horizontal axis; only an area of the original image has been considered (defined by the four points); (g) symmetry in the horizontal axis, after rotating the original image; aspect ratio changed; h) symmetry in the vertical axis, after reordering the four points defining the considered area. 


\section{Results}

In this section, we show the results of extracting and completing the design of textiles with the Virtual Loom, by making use of the symmetry functionality. Garin 1820 is a historical industry that still weaves with techniques and with historical designs, so it is important to put technology at the service of the conservation of living heritage.

We have used some examples extracted from Garín's dataset, which is composed of 2028 objects, from which 1083 are fabrics, and 1045 of technical drawings. After inspecting them, we have found the following cases, in which the use of the symmetry functionality of the Virtual Loom can be helpful to extract the original design (referred to as types of defects from now on):

A. One part of the object is missing: broken areas; the object is not entirely pictured; only one part was produced (technical drawings).

B. The object is partially bent, so there is a hidden part.

C. There are wrinkles.

D. There is an artifact (e.g., labels) occluding part of the object.

E. Parts of the object are dirty or scratched.

F. Light on the object is not uniform: some areas are too bright or too dark; there are shadows; etc.

G. Some parts of the image are blurred/unfocused.

From the total set of objects, we have counted those that, being symmetrical, have at least one type of defect (from A to G). A total of 759 images meet that condition ( $36 \%$ of the total). From this, 157 are technical drawings ( $15 \%$ of the images of technical drawings) and 602 fabrics (56\%). In Figure 4 , the total amount of images holding each of the defects is shown, discerning also between technical drawings and fabrics. Note that a single image can have more than one type of defect. It has to be added that, in this dataset, symmetries are mainly only with respect to a vertical axes (from the total of 759 images, 135 technical drawings and 574 fabrics), and only some samples have both vertical and horizontal symmetries (from the total of 759 images, 22 technical drawings and 28 fabrics); none of the designs have only a horizontal symmetry.

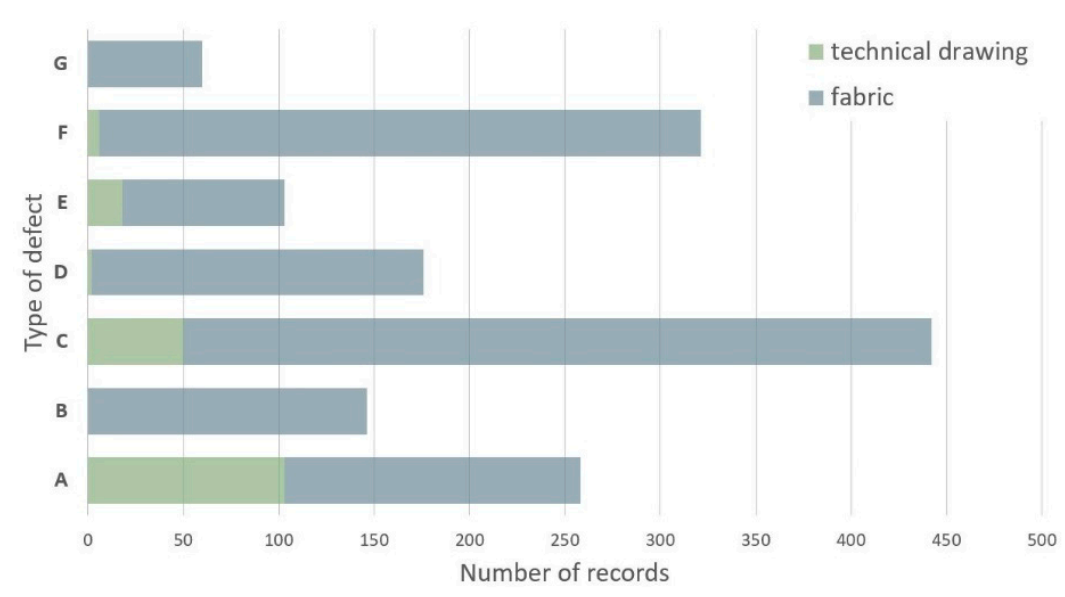

Figure 4. Types of defects (A to G) found in Garín's dataset, for those images (technical drawings or fabrics) that have at least one symmetrical axis (vertical; vertical and horizontal). Samples might have more than one defect.

In the following images, we show some examples having one or more of the defects listed above (from A to G). Then, we extract the original design by making use of the symmetry functionality, to finally produce a $3 \mathrm{D}$ representation of the fabric at the yarn level. The first example is given in Figure 5 . In this case, the original image was acquired with a scanner, with limited dimensions. Therefore, although the fabric was complete, the complete design is missing in the image (defect A). This design 
corresponds to a Soto; a model that presents a stylized floral decoration. The upper part has a display of fan leaves like a crest, that is emphasized with a slight bouquet of carnations. The top looks like two symmetrical flowers that are collected between flower buds and leaves and bouquets that radiated from a central flower. This central motif is framed with scrolls that embrace pampas and grape clusters that come from a stylized vine. The design was obtained by applying the symmetry function with respect to the vertical axes. The sample corresponds to a fabric with espolín weaving technique.

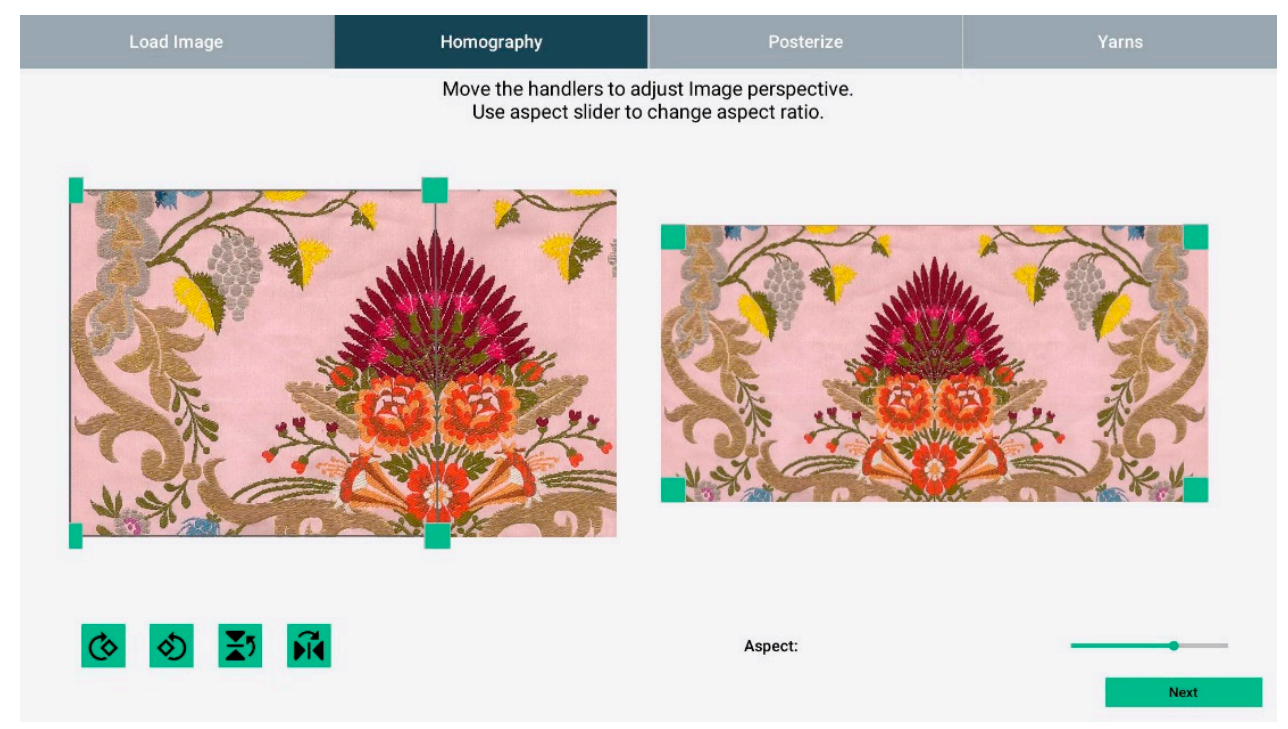

(a)

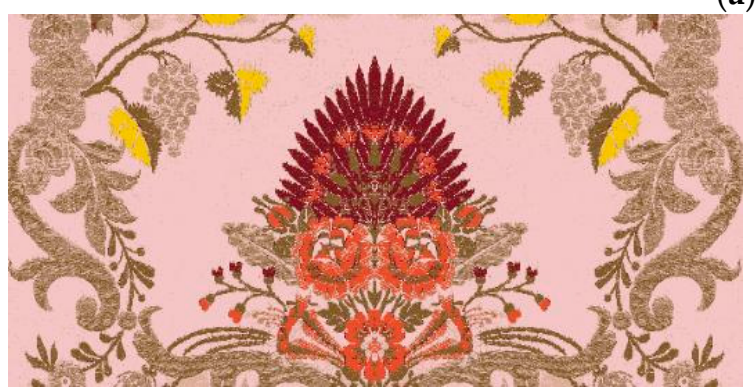

(b)

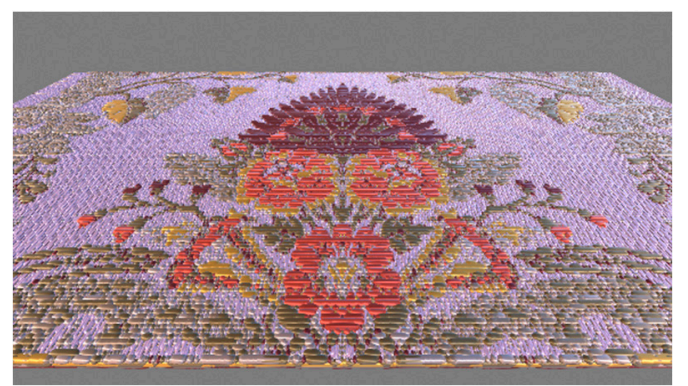

(c)

Figure 5. Subtracting the design of a fabric with defect A (only part of the object was pictured), where: (a) Original image and result after applying the symmetry functionality; (b) Reconstructed design; (c) 3D model.

In Figure 6, we show an example of a technical drawing which is formed by a centered flower bouquet framed by a poly-lobed structure decorated with trellis and acanthus leaves, in which garlands of flowers are intertwined with similar structures. This drawing has only half of the design (defect A). This characteristic is quite common in technical drawings that have an axis of symmetry, as only half of the image needs to be produced. In drawings with a vertical and a horizontal axis of symmetry, only one fourth of the technical drawing might be produced. To subtract the design, the image was first flipped by reordering the four points, and then the symmetry option was applied with respect to the vertical axis. The sample was woven in the Virtual Loom by making use of the damask technique.

Figure 7 depicts a fabric with an Asunción design, where one part is missing because it is broken (defect A). In this case, the four points were located in such a way that most of the original design was covered, and then the symmetry was applied with respect to the vertical axis. Then, the fabric was woven in the Virtual Loom as a damassé with metallic weft. This model is a floral representation that follows the pattern of the grottos applied to the floral composition, with a vertical development. 
The central motif develops as a crescendo baluster shaft that is flanked by identical flowers and a fringe of small flowers that culminate in a single flower. The central design is framed symmetrically by two compositions of stylized leaves and central flower.

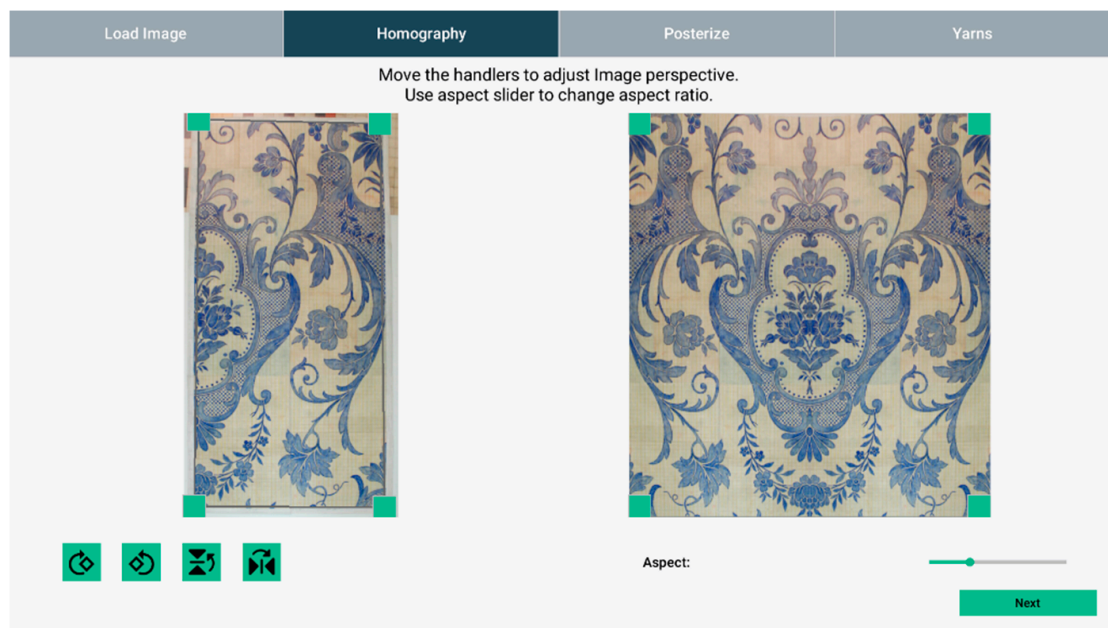

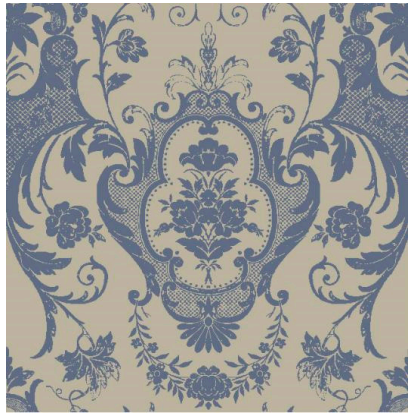

(b) (a)

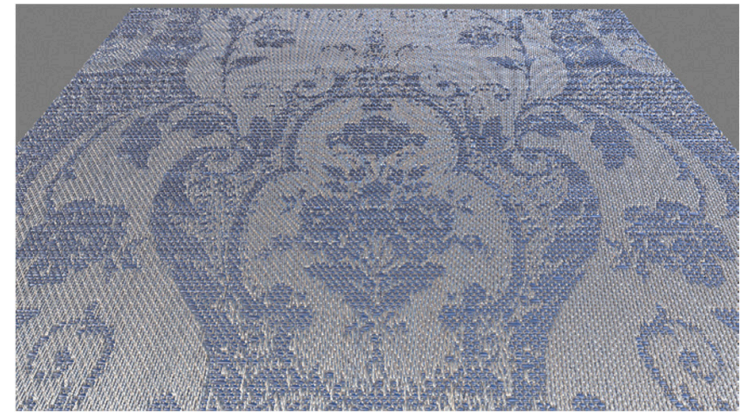

(c)

Figure 6. Subtracting the design of a technical drawing with defect A (only half of the object was produced), where: (a) Original image and result after applying the symmetry functionality; (b) Reconstructed design; (c) 3D model.

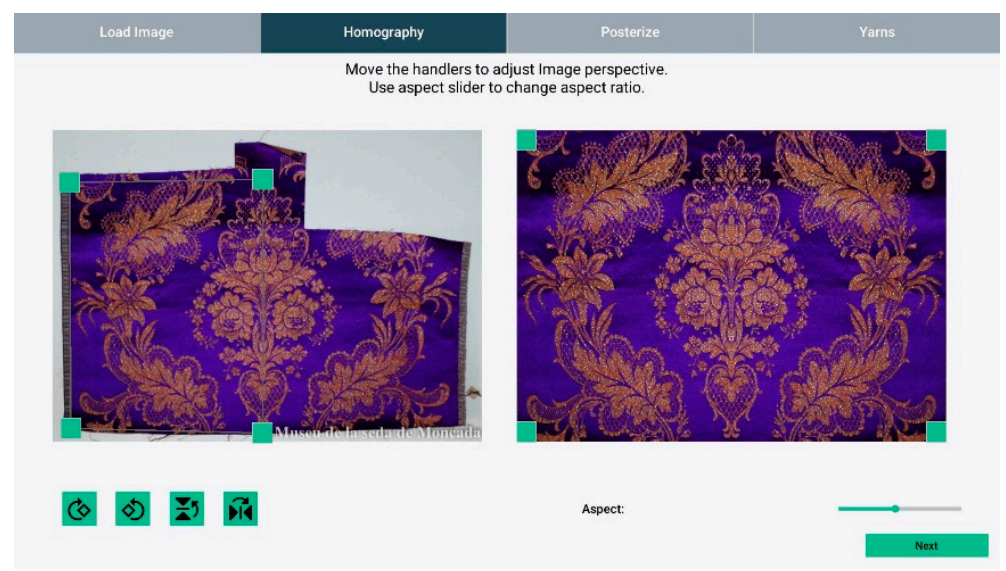

(a)

Figure 7. Cont. 


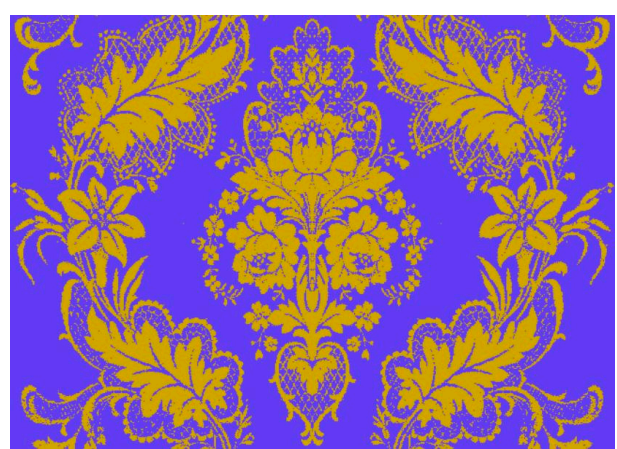

(b)

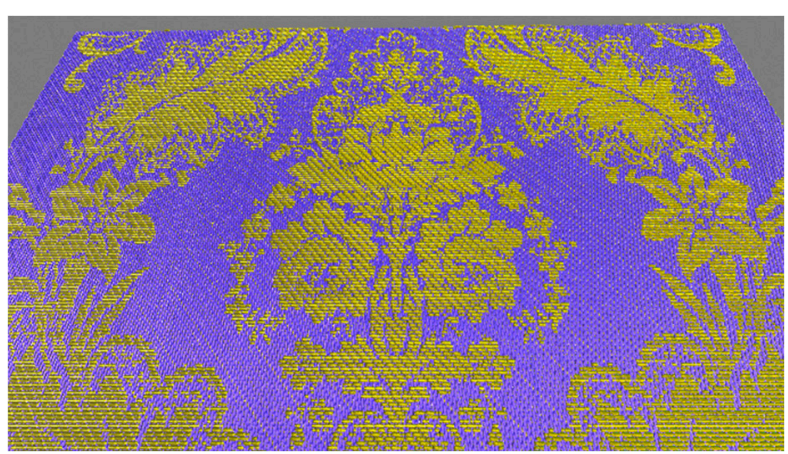

(c)

Figure 7. Subtracting the design of a fabric with defect A (broken area), where: (a) Original image and result after applying the symmetry functionality; (b) Reconstructed design; (c) 3D model.

The fabric shown in Figure 8 shows a revival of Byzantine design which has vertical and horizontal symmetries, but the complete design is missing: as can be seen, the design is composed of circles as the main figure, but none of them is complete (defect A). It is a geometric composition of floral efflorescence developed in the form of a cross and inserted into medallions that are knotted with loops in their diameters.

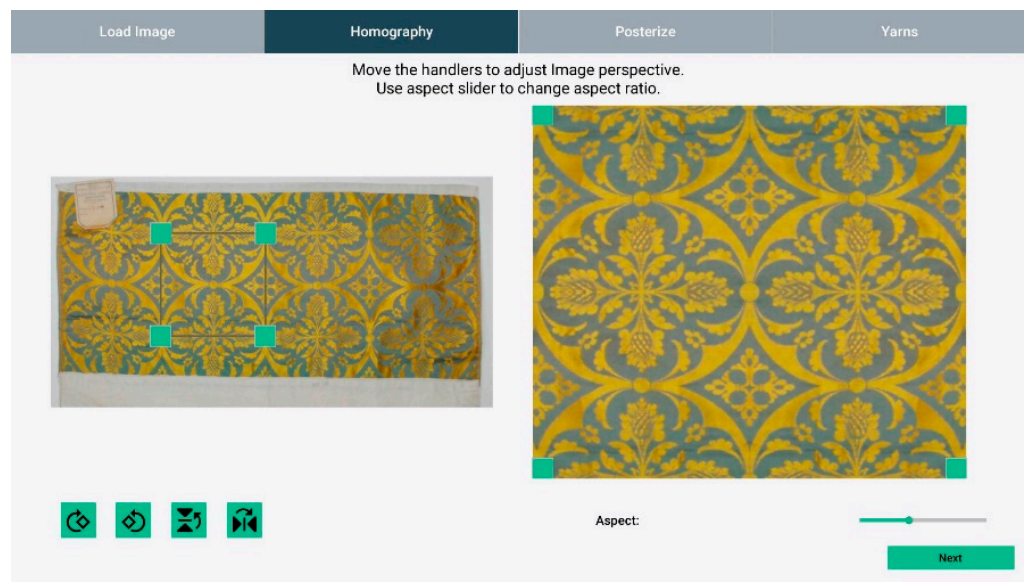

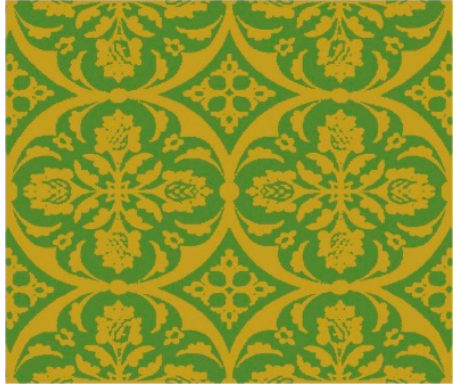

(b) (a)

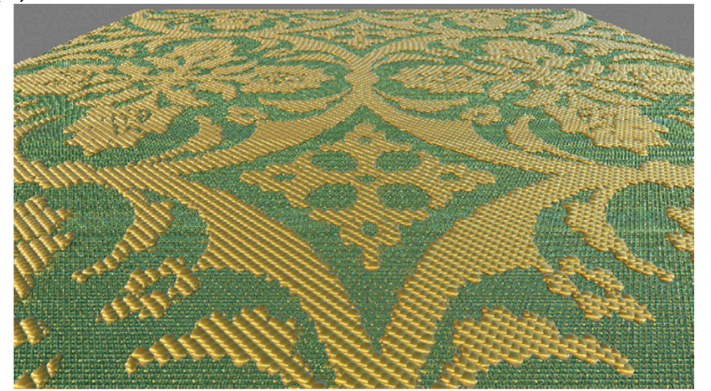

(c)

Figure 8. Subtracting the design of a fabric with defects A, C, D and F, where: (a) Original image and result after applying the symmetry functionality; (b) Reconstructed design; (c) 3D model.

Additionally, there is an artifact to the right top area, above one of the circles (defect D), and there are some wrinkles on the left side of the fabric (defect $\mathrm{C}$ ) that, in this case, produce some shadows (defect F). In this case, the design was subtracted by making use of symmetries, both vertically and horizontally. After subtracting the design, this fabric was woven in the Virtual Loom as a lampas. This image was originally weaved as a brocatelle (A fabric imitating a brocade with high decorative reliefs, 
to make hangings and other uses on furniture), but in SILKNOW we weaved it as a lampas (generally the a figured compound weave, to produce luxurious figured silks, in which a pattern, composed of weft floats bound by a binding warp, is added to a ground weave formed by a main warp and a main weft); this decision was made after discussing with domain experts who wished to show this historical weaving technique and its difficulty.

The image in Figure 9 depicts a fabric with wrinkles (defect C) and a label that hides part of the design (defect D). A central-left part of the drawing was selected with the four points, and the symmetry was applied with respect to the vertical axis. In this case, the design was subtracted by making use of only five areas (note that the original fabric has more colors than the resulting one) and it was woven as an espolín. This model presents the development of a single flower, of exotic appearance, that centers the composition and closes in its lower part with leaves that develop the stem that, in turn, apes in a symmetrical garland of small flowers. The floral structure marks the center of a variegated plant composition in a rhomboid shape.

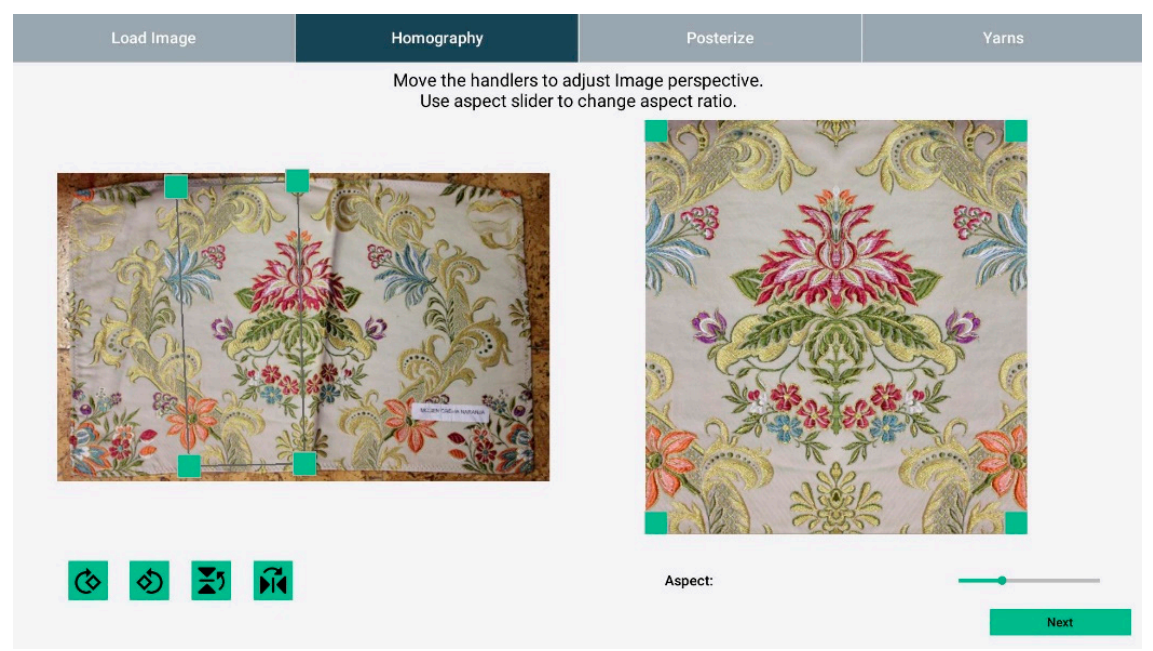

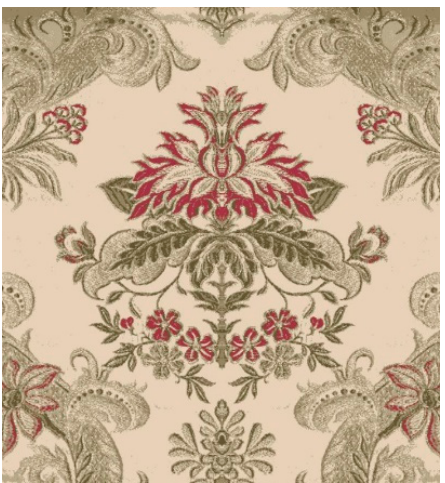

(b)

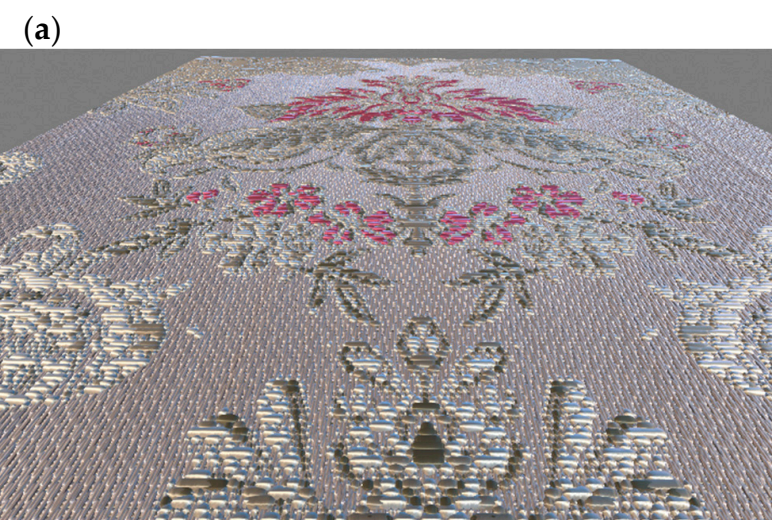

(c)

Figure 9. Subtracting the design of a fabric with defects $C$ and $D$, where: (a) Original image and result after applying the symmetry functionality; (b) Reconstructed design; (c) 3D model.

Apart from subtracting the original design of a technical drawing or a fabric, the symmetry functionality in the Virtual Loom can also be used to create new designs, given an input image. This is depicted in the following figures (Figures 10-12), where the Agües design has been modified. In this case, the design is a synthetic version of the Asunción model in the central structure. In this variant baluster, forms have been eliminated by a more vegetal development and naturalistic visuality. This visuality is enhanced by the organic forms of the floral bouquets which, in the form of a blade, radiate, maintaining symmetry from the central composition. 


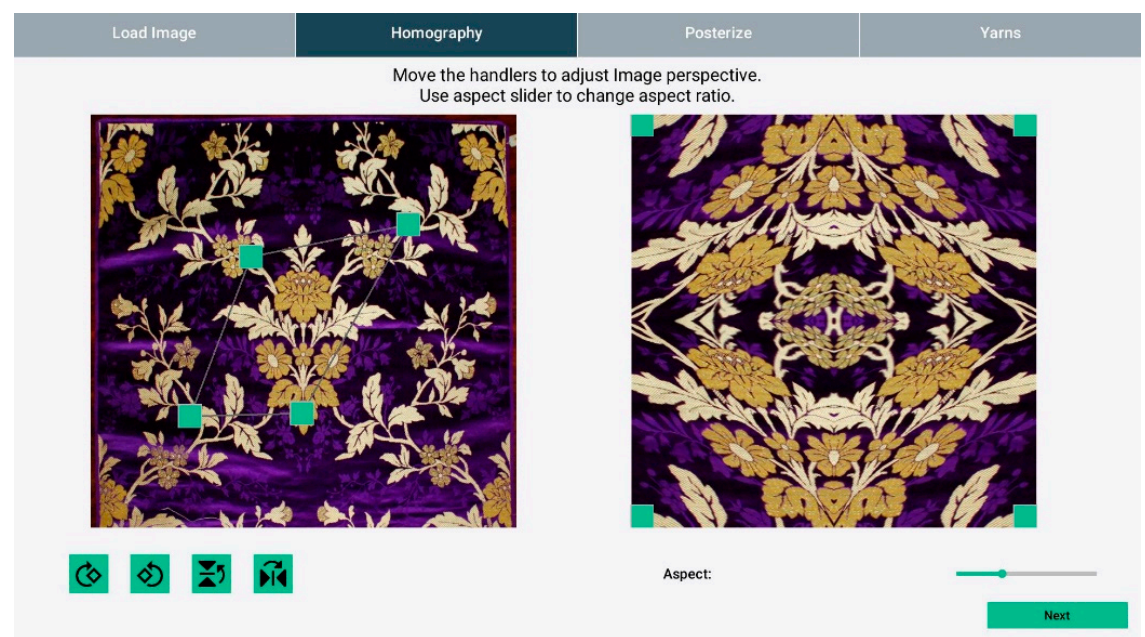

Figure 10. An example for creating new designs in the Virtual Loom, given an input image. The area within the four points (left image), holds most of the central motive.

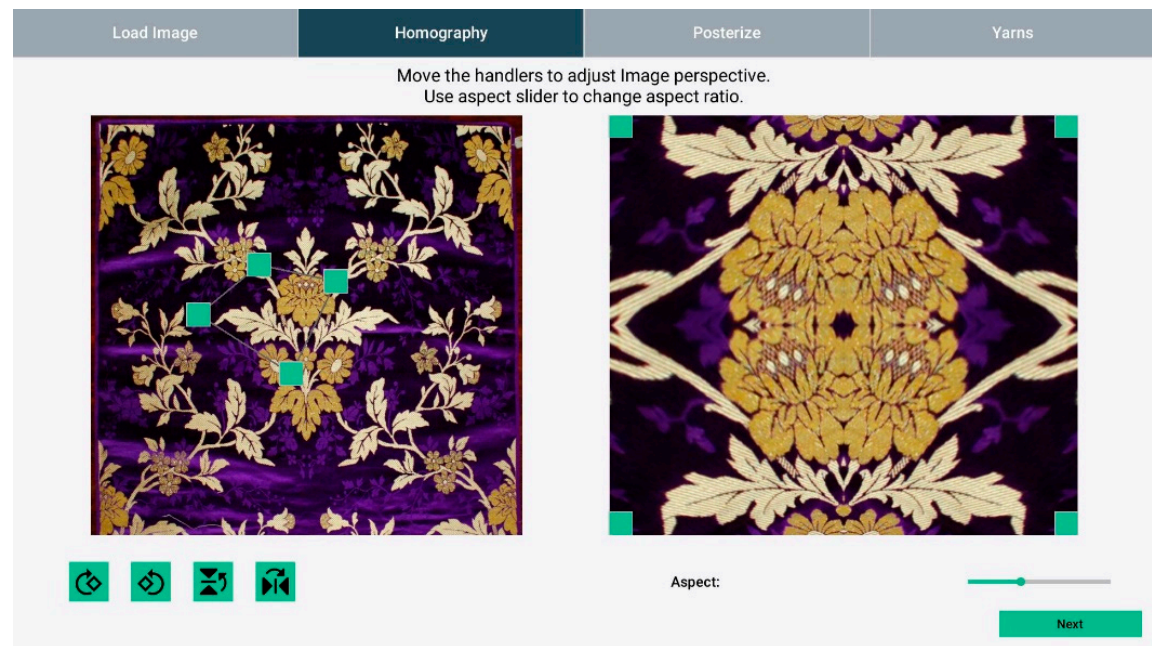

Figure 11. An example of creating new designs in the Virtual Loom, given an input image. The area within the four points (left image), holds only part of the central motive.

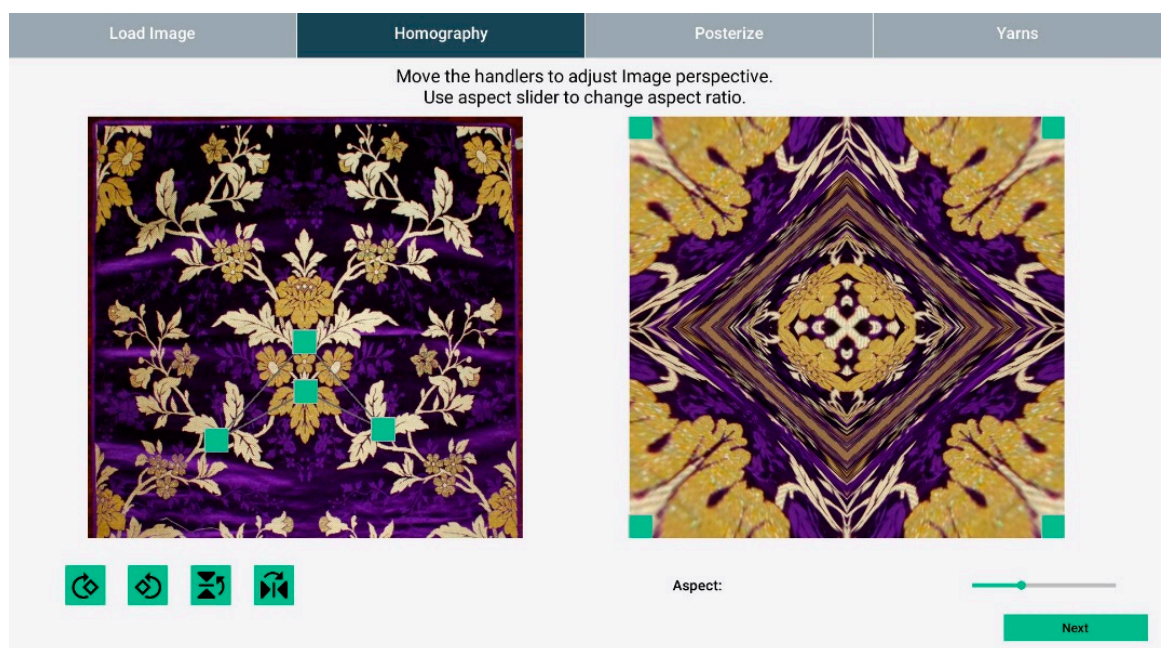

Figure 12. An example of creating new designs in the Virtual Loom, given an input image. The area within the four points (left image), holds only part of the central motive, and the four points do not form a convex hull. 
Departing from a single image of a historical fabric, different designs are created by applying the symmetry functionality, changing the location of the four points and adjusting the aspect ratio. For all cases, the images have been mirrored twice (through the vertical and the horizontal axis).

Finally, the first version of the Virtual Loom was tested among domain experts, that is, an artisanal weaver, a conservator (from the consortium) and a visual artist. This pilot was done after showing them a video tutorial (not yet public) on how to use the virtual loom. In all three cases, the result was positive. While the visual artist saw it as a way of enriching her artistic work by being able to transfer her designs to weaving, the symmetry function allows her to further modify those designs and explore new paths of creativity. The curator indicated how the symmetry function accelerates the process of designs reconstruction, resulting in the rapid visualization of the type of disposition, hence helping to better catalogue and study fabrics stylistic evolution. In addition, the possibility of using it as a teaching prop for children and people with special abilities means bringing fabrics closer to the general public. Finally, the artisanal weaver, besides contributing with valuable indications to improve the virtual loom, pointed out how the symmetry functionality can boost the knowledge of historical fabrics, that in turn they can learn, document and recreate.

\section{Discussion}

In the results section, we have reconstructed some historical designs, by making use of the symmetry functionality of the Virtual Loom. Furthermore, we have analyzed the complete dataset of Garin, by quantifying those cases that, having a symmetrical axis, present types of defects that make it difficult to extract their original design. These images represent $36 \%$ of the dataset. For these cases, the symmetry function of the Virtual Loom can aid reconstructing them. As seen from these results, the symmetry functionality of the Virtual Loom allows reconstructing missing parts, both in technical drawings and in fabrics. These results show the conservative, methodological and interpretative advantages of symmetry analysis applied to historical designs.

Regarding conservation, some projects have already been carried for the total or partial reconstruction of certain cultural objects. The use of ICT tools that apply symmetry in their software development is especially useful in those assets that, due to natural causes, bad conservation, natural disasters or human activity, have led to the loss of certain fragments. To reconstruct, document and preserve cultural objects with missing elements has led curators and restorers to apply manual processes that can be too time-consuming and require specific expertise. The use of digital procedures that correct symmetry axes are a major step towards protecting cultural heritage. In that sense, some experiments have already been carried out, such as the chisel copper and gilding decoration in architectural palaces [50], damaged pottery from the Larco Museum in Perú [51], or Valencian tiles [52]; these are just some examples of how symmetry analysis becomes a helpful tool to support other tasks, such as object reconstruction or image analysis and recognition. The Virtual Loom, on one hand, carries out the important task of documenting and preserving historical weaving techniques that are at risk of disappearing because of the imminent closure of the factories that are still weaving in an artisanal way, but also because of the lack of young generations who want to work in this ancestral job. Furthermore, thanks to the symmetry function, the Virtual Loom allows the reconstruction of missing elements in both the preparatory drawings and the fabrics themselves, allowing curators to get an idea of how these assets looked originally. Finally, thanks to its ability to generate STL files, it permits the 3D printing of the objects. Hence, it becomes a didactic prop that allows the general public to access and understand historical weaving techniques, but it also gives access to this fragile heritage to people with special skills. For example, in Figures 5 and 6, the Virtual Loom allowed one to complete patterns. In the first case, it not only helped to complete the design, but it also was translated to weaving; therefore, it provided a new fabric that, without the punched card and the complete design, would be extremely complicated to be weaved. In the second case, it depicts the missing part, allowing one to fully complete the pattern. 
On the other hand, symmetry analysis applied to textiles can lead to new methodological approaches, in order to study both patterns and stylistic evolution. Knowledge of geometric principles applied to textile art can become a problem solver when classifying and analyzing patterns and styles. Symmetric classification relies on standardized and delimited units that allow comparative studies over time and space, facilitating to researchers (art historians, historians, anthropologists, designers, etc.) the formation of new hypotheses. In this sense, this mathematical approach ensures that a researcher can investigate several data that will be able to consistently describe a motif, pattern or style $[2,53]$. Symmetry classification, on one hand, can isolate attributes that are specific to a particular time or location, and as such, it can become a relevant indicator of continuity, changes, or even to better comprehend revivals at the time it has proved to be useful in comparing different cultures and their influences. Indeed, in order to fully understand stylistic features, single items facilitate the iconographic significance but also, distribution and correlation among elements. Nevertheless, to fully understand how a style evolves in time and space deeper research must be conducted, a symmetrical analysis can take place, together with other more conventional investigations, where the yarns, colors, forms and techniques are also taken into account [54]. These inquiries can lead towards new interpretations of historical textile designs, especially in the European silk context, where ideas, designs and technology were widely spread along with these networks, making their origin and evolution sometimes complicated.

Finally, designs are the result of someone's imagination. Textile collections can become an invaluable resource for artists, artisans and designers. As Valiente et al. [52] state: 'designers creative work often begins by searching and redesigning successful elements from preceding collections'. In this regard, the Virtual Loom can be used to create new designs departing from historical ones. As Figure 10 shows, the design was modified to create a completely new design thanks to the symmetry functionality.

Author Contributions: Conceptualization, C.P. and J.S.; Methodology, C.P. and J.S.; vaLidation, C.P. and M.G.; Formal analysis, M.G. and C.P..; Investigation, C.P., M.G. and E.A..; Resources, M.G. and E.A.; Data curation, M.G., E.A. and J.S.; Writing-Original draft preparation, M.G., C.P. and E.A.; Writing-Review and editing, M.G., C.P. and E.A.; Visualization, C.P. and J.S.; Funding acquisition, M.G., C.P., E.A. and J.S. All authors have read and agreed to the published version of the manuscript.

Funding: The research leading to these results is in the frame of the "SILKNOW. Silk heritage in the Knowledge Society: from punched cards to big data, deep learning and visual/tangible simulations" project, which has received funding from the European Union's Horizon 2020 research and innovation program under grant agreement No. 769504.

Acknowledgments: Cristina Portalés is supported by the Spanish government postdoctoral grant Ramón y Cajal. Authors would like to thank researchers Pablo Casanova-Salas and Manolo Pérez, who are involved in the implementation of the Virtual Loom.

Conflicts of Interest: The authors declare no conflict of interest.

\section{References}

1. Avital, T. Symmetry: The connectivity principle of art. Symmetry Cult. Sci. 1996, 7, 27-50.

2. Brezine, C. Creating Symmetry on the Loom; University of Washington Press: Washington, DC, USA, 2004.

3. Legino, R.; Forrest, D. Symmetrical motif design in Malaysian batik sarong patterns. In International Colloquium of Art and Design Education Research (i-CADER 2014); Hassan, O.H., Abidin, S.Z., Legino, R., Anwar, R., Kamaruzaman, M.F., Eds.; Springer Science and Business Media: Singapore, 2015; pp. 695-701.

4. Portalés, C.; Sevilla, J.; Pérez, M.; León, A. A Proposal to Model Ancient Silk Weaving Techniques and Extracting Information from Digital Imagery-Ongoing Results of the SILKNOW Project. In International Conference on Computational Science; Springer: Berlin/Heidelberg, Germany, 2019.

5. Portalés, C.; Alonso-Monasterio, P.; Viñals, M.J. 3D virtual reconstruction and visualisation of the archaeological site Castellet de Bernabé (Llíria, Spain). Virtual Archaeol. Rev. 2017, 8, 75-82. [CrossRef]

6. Rua, H.; Alvito, P. Living the past: 3D models, virtual reality and game engines as tools for supporting archaeology and the reconstruction of cultural heritage-The case-study of the Roman villa of Casal de Freiria. J. Archaeol. Sci. 2011, 38, 3296-3308. [CrossRef] 
7. Granero-Montagud, L.; Portalés, C.; Pastor-Carbonell, B.; Ribes-Gómez, E.; Gutiérrez-Lucas, A.; Tornari, V.; Papadakis, V.; Groves, R.M.; Sirmacek, B.; Bonazza, A.; et al. Deterioration Estimation of Paintings by Means of Combined 3D and Hyperspectral Data Analysis. In Proceedings of the SPIE Optical Metrology 2013, Munich, Germany, 13-16 May 2013; Volume 8790, p. 879008.

8. Chow, S.-K.; Chan, K.-L. Reconstruction of photorealistic 3D model of ceramic artefacts for interactive virtual exhibition. J. Cult. Herit. 2009, 10, 161-173. [CrossRef]

9. Arbace, L.; Sonnino, E.; Callieri, M.; Dellepiane, M.; Fabbri, M.; Iaccarino Idelson, A.; Scopigno, R. Innovative uses of 3D digital technologies to assist the restoration of a fragmented terracotta statue. J. Cult. Herit. 2013, 14, 332-345. [CrossRef]

10. Guidi, G.; Beraldin, J.-A.; Atzeni, C. High-accuracy 3D modeling of cultural heritage: The digitizing of Donatello's Maddalena. IEEE Trans. Image Process. 2004, 13, 370-380. [CrossRef] [PubMed]

11. Gimeno, J.; Portalés, C.; Coma, I.; Fernández, M.; Martínez, B. Combining Traditional and Indirect Augmented Reality for Indoor Crowded Environments. A Case Study on the Casa Batlló Museum. Comput. Graph. 2017, 69, 92-103. [CrossRef]

12. Martínez, B.; Casas, S.; Vidal-González, M.; Vera, L.; García-Pereira, I. TinajAR: An Edutainment Augmented Reality Mirror for the Dissemination and Reinterpretation of Cultural Heritage. Multimodal Technol. Interact. 2018, 2, 33. [CrossRef]

13. Etzmuss, O.; Keckeisen, M.; Strasser, W. A fast finite element solution for cloth modelling. In Proceedings of the 11th Pacific Conference on Computer Graphics and Applications, Canmore, AB, Canada, 8-10 October 2003; pp. 244-251.

14. Jiang, Y.; Chen, X. Geometric and algebraic algorithms for modelling yarn in woven fabrics. J. Text. Inst. 2005, 96, 237-245. [CrossRef]

15. Cirio, G.; Lopez-Moreno, J.; Otaduy, M.A. Efficient Simulation of Knitted Cloth Using Persistent Contacts. In Proceedings of the 14th ACM SIGGRAPH/Eurographics Symposium on Computer Animation, Los Angeles, CA, USA, 7-9 August 2015; ACM: New York, NY, USA, 2015; pp. 55-61.

16. Kaldor, J.M.; James, D.L.; Marschner, S. Simulating Knitted Cloth at the Yarn Level. In Proceedings of the ACM SIGGRAPH 2008 Papers, Los Angeles, CA, USA, 11-15 August 2008; ACM: New York, NY, USA, 2008; pp. 65:1-65:9.

17. Wu, K.; Yuksel, C. Real-time Fiber-level Cloth Rendering. In Proceedings of the 21st ACM SIGGRAPH Symposium on Interactive 3D Graphics and Games; ACM: York, NY, USA, 2017; pp. 5:1-5:8.

18. Lomov, S.V. WiseTex Software Suite. Available online: https:/www.mtm.kuleuven.be/Onderzoek/ Composites/software/wisetex (accessed on 23 November 2019).

19. Lomov, S.V. Modelling the Geometry of Textile Composite Reinforcements: WiseTex; Elsevier: Amsterdam, The Netherlands, 2011.

20. TexGen. Available online: http://texgen.sourceforge.net/index.php/Main_Page (accessed on 23 November 2019).

21. Pointcarré Textile Software. Available online: https://www.pointcarre.com/ (accessed on 4 December 2019).

22. STOLL M1 Plus. Available online: https://www.stoll.com/en/software/m1plusr/ (accessed on 4 December 2019).

23. iWeaveIt. Available online: http://www.weaveit.com/iWeaveIt.aspx (accessed on 4 December 2019).

24. McBurney, S. On constructing a virtual loom. In Proceedings of the Conference of Bridges: Mathematics, Music, Art, Architecture, Culture, Banff, AB, Canada, 26-30 July 2009; pp. 287-292.

25. Eglash, R. Re-thinking symmetry in ethno-mathematics. Symmetry Cult. Sci. 2003, 12, 159-166.

26. Gang, Z.; Bingbing, D.; Wenjuan, Z.; Yali, Y.; Hui, Z. Design and implementation of interactive system for Tujia brocade virtual weaving based on kinect. In Proceedings of the 2017 23rd International Conference on Automation and Computing (ICAC), Huddersfield, UK, 7-8 September 2017; pp. 1-5.

27. Portalés, C.; Sebastián, J.; Alba, E.; Sevilla, J.; Gaitán, M.; Ruiz, P.; Fernández, M. Interactive tools for the preservation, dissemination and study of silk heritage-An introduction to the silknow project. Multimodal Technol. Interact. 2018, 2, 28. [CrossRef]

28. Adam, J. (Ed.) The Republic of Plato; Cambridge University Press: Cambridge, UK, 1902.

29. Arnzen, R. (Ed.) On Aristotle's" Metaphysics": An annotated translation of the so-called" Epitome"; Walter de Gruyter: Berlin, Germany, 2010; Volume 5.

30. López, G. Belleza y simetría: Una historia de preferencia cultural. In Congreso Forma y Simetría: Arte y Ciencia; Congreso de Buenos Aires: Buenos Aires, Argentina, 2007; pp. 318-321. 
31. Darvas, G. Symmetry: Cultural-Historical and Ontological Aspects of Science-Arts Relations; The Natural and Man-Made World in an Interdisciplinary Approach; Springer Science \& Business Media: Basel, Switzerland, 2007.

32. Rohde, G.M. Simetria: Rigor e Imaginação; EDIPUCRS: Porta Alegre, Brazil, 1997.

33. Giora, H.; Goldstein, B.R. From Summetria to Symmetry: The Making of a Revolutionary Scientific Concept; Springer Science \& Business Media: Berlin, Germany, 2008.

34. Monge, G. Geometría Descriptiva, Lecciones Dadas en las Escuelas Normales en el Año Tercero de la República; Imprenta Real: Madrid, Spain, 1803.

35. Calvo López, J. Gaspard Monge, la estética de la Ilustración y la enseñanza de la Geometría Descriptiva. Rev. De Expresión Gráfica En La Edif. 2006, 4, 85-92. [CrossRef]

36. Alegre Cremades, A. La enseñanza de las artes. In La Academia de Santa Bárbara y la Real de las Tres Nobles Artes de San Carlos, Cien años de Enseñanza de Arte; Universitat Politècnica de Valencia: Valencia, Spain, 2004; pp. 75-78.

37. Gombrich, E.H. The Sense of Order: A Study in the Psychology of Decorative Art, 2nd ed; Phaidon: Oxford, UK, 1984.

38. Fernaeus, Y.; Jonsson, M.; Tholander, J. Revisiting the jacquard loom: Threads of history and current patterns in HCI. In Proceedings of the SIGCHI Conference on Human Factors in Computing Systems; Association for Computing Machinery: New York, NY, USA, 2012; pp. 1593-1602.

39. Sergeev, A.; Sergeev, M.; Vostrikov, A.; Kurtyanik, D. Portraits of Orthogonal Matrices as a Base for Discrete Textile Ornament Patterns. In Intelligent Decision Technologies 2019; Czarnowski, I., Howlett, R., Jain, L., Eds.; Springer: Singapore, 2019; pp. 135-143.

40. Lekka, L.; Dascalopoulos, S. Motifs and Symmetry Characteristics of the Ornamentation on Traditional Greek Woven Textiles from the Area of the Aegean. Fibres Text. East. Eur. 2008, 16, 74-78.

41. Hann, M.A. The fundamentals of pattern structure: Part I: Woods revisited. J. Text. Inst. 2003, 94, 53-65. [CrossRef]

42. Kraft, K. Textile patterns and their epistemological functions. Textile 2004, 2, 274-289. [CrossRef]

43. Brainerd, G.W. Symmetry in primitive conventional design. Am. Antiq. 1942, 8, 164-166. [CrossRef]

44. Alba, E.; Gaitán, M.; León, A.; Sebastián, J. Spanish Religious Textiles from the 18th and 19th centuries: The Garín case. Eur. J. Sci. Theol. 2020, 16, 187-197.

45. McLean, A.; Harlizius-Klück, E.; Jefferies, J. Introduction: Weaving Codes, Coding Weaves. Textile 2017, 15, 118-123. [CrossRef]

46. Gaitán, M.; Alba, E.; León, A.; Pérez, M.; Sevilla, J.; Portalés, C. Towards the Preservation and Dissemination of Historical Silk Weaving Techniques in the Digital Era. Heritage 2019, 2, 1892-1911. [CrossRef]

47. Available online: https://github.com/silknow/virtual-loom (accessed on 1 April 2020).

48. Available online: https://silknow.eu/virtualLoom/ (accessed on 1 April 2020).

49. Virtual Loom, Tutorial. Available online: https://www.youtube.com/watch?v=oaZqM3-Wli8 (accessed on 4 April 2020).

50. Zhou, P.; Shui, W.; Qu, L.; Gao, F.; Wu, Z. Case study: Missing data computation and 3D printing application in symmetrical artifact restoration. In Proceedings of the Symposium on VR Culture and Heritage, Zhuhai, China, 3-4 December 2016; Volume 2, pp. 63-66.

51. Ivan, S. Analysis of partial axial symmetry on $3 \mathrm{~d}$ surfaces and its application in the restoration of cultural heritage objects. In Proceedings of the IEEE International Conference on Computer Vision (ICCV), Venice, Italy, 22-29 October 2017.

52. Valiente, J.M.; Albert, F.; Carretero, C.; Gomis, J.M. Structural description of textile and tile pattern designs using image processing. In Proceedings of the 17th International Conference on Pattern Recognition, Cambridge, UK, 23-26 August 2004; ICPR: Cambridge, UK, 2004; Volume 1, pp. 498-503.

53. Washburn, D.K. Analysis of Pattern Structure by Geometric Symmetries. In Textile Society of America Symposium Proceedings; Textile Society of America: Minneapolis, MN, USA, 1998; pp. 40-44.

54. Moxey, J. Textile design: A holistic perspective. J. Text. Inst. 1992, 90, 176-181. [CrossRef] 